\title{
The Diverging Dictionaries of Science and Law
}

\author{
Helena Likwornik ${ }^{1}$ (Co-Author) and Jason Chin ${ }^{2}$ (Co-Author) \\ Maya Bielinski ${ }^{3}$ (Contributor)
}

\footnotetext{
${ }^{1}$ Co-author (study concept). University of Toronto Faculty of Law, Adjunct Professor. The views expressed in this paper reflect Helena Likwornik's personal views and are not intended to represent the views of the institutions with which she is affiliated.

${ }^{2}$ Co-author (data analysis design). T.C. Beirne School of Law, University of Queensland; University of Toronto Faculty of Law.

${ }^{3}$ Contributor (existing efforts to standardize terminology). University of Toronto Faculty of law student. Currently articling at Gilbert's LLP.
} 


\begin{abstract}
Scientific evidence is easily misunderstood. One of the most insidious instances of misunderstanding arises when scientific experts and those receiving their evidence assign different meanings to the same words. We expect scientific evidence to be difficult to understand. What is unexpected, and often far more difficult to detect, is the incorrect understanding of terms and phrases that appear familiar. In these circumstances, misunderstandings easily escape notice. We applied an evidence-based approach to investigating this phenomenon, asking two groups, one with legal education and one with scientific education, to define five commonly-used phrases with both lay and scientific connotations. We hypothesized that the groups would significantly diverge in the definitions they provided. Employing a machine learning algorithm and the ratings of trained coders, we found that lawyers and scientists indeed disagreed over the meanings of certain terms. Notably, we trained a machine learning algorithm to reliably classify the authorship of the definitions as scientific or legal, demonstrating that these groups rely on predictably different lexicons. Our findings have implications for recommending avoidance of some of these particular words and phrases in favour of terminology that promotes common understanding. And methodologically, we suggest a new way for governmental and quasi-governmental bodies to study and thereby prevent misunderstandings between the legal and scientific communities.
\end{abstract}




\section{Introduction}

The limits of language mean the limits of my world. ${ }^{4}$

The difference between the almost right word $\&$ the right word is really a large

matter-it's the difference between the lightning bug and the lightning. ${ }^{5}$

Speak clearly, if you speak at all; carve every word before you let it fall. ${ }^{6}$

Words carry great power. This paper explores this power in the context of scientific evidence and the law. As science continues to learn more about the world, few areas remain beyond its reach. Expert scientific evidence can be central to cases concerning medical malpractice, the safety and efficacy of drugs and chemicals, the use of blood tests to determine paternity, and the interpretation of DNA findings. At the same time, the very quality that renders expert evidence necessary, namely, that it is outside the fact-finder's ken, also gives rise to the danger that it will be improperly applied or misunderstood.

One facet of this danger pertains to the language of science. It is well known that scientists often use special words or expressions that are known within their professional community but are difficult for others to understand. We will refer to such terminology throughout as "jargon". Jargon can either be "obvious" or "non-obvious". With obvious jargon, the difficult in understanding the terms used is apparent. For example, if a medical practitioner speaks of "Calot's triangle", it will usually be apparent, or obvious, that this phrase needs to be explained to a lay person. ${ }^{7}$ With non-obvious jargon, on the other hand, the words used have a special meaning within a particular discipline, but the existence of this special meaning is not

\footnotetext{
${ }^{4}$ Ludwig Wittgenstein. Tractatus Logico-Philosophicus. Kegan, Paul (London), 1922.

${ }^{5}$ Mark Twain (Samuel L. Clemens). - George Bainton, The Art of Authorship, pp. 87-88 (1890).

${ }^{6}$ Oliver Wendell Holmes. The Path of the Law and The Common Law (2009 edition), Kaplan Publishing

7 "Calot's triangle" refers to the cystic duct, the common duct, and the liver.
} 
necessarily apparent. For example, when lawyers use the term "spouse" in the context of discussing property rights under the Family Law Act, RSO 1990, c F.3, they are likely referring to married spouses. This is because the term "spouse" is defined under that part of the legislation as only those who are married. To a lay person, however, the word "spouse" is easily understood but is likely to mean something different: namely, anyone in a conjugal relationship of some permanency. Part of the Canadian test for admitting expert evidence is whether the expert can "address the issue in understandable terms". ${ }^{8}$ As Justice Sopinka reminded us in $R v$ Mohan, there is a real concern that expert evidence that is "dressed up in scientific language which the jury does not easily understanding" will be misused. ${ }^{9}$ Similarly, Justice Moldaver's application of a threshold test of reliability for expert evidence in $R v$ Melaragni asks whether the jury is likely to be overwhelmed by the "mystic infallibility" of the evidence. ${ }^{10}$ All too often, scientists who provide opinion evidence, in the form of written and/or oral testimony, are not understood. As one juror put it in a Merck Vioxx case, "Whenever Merck was up there it was like "wah wah wah"...we didn't know what the heck they were talking about."11

${ }^{8} R \cup D(D), 2000$ SCC 43 at para 40, 191 DLR (4th) 60.

9 [1994] 2 SCR 9 at para 23, 89 CCC (3d) 402.

${ }_{10}(1992), 73 \mathrm{CCC}(3 \mathrm{~d}) 348$ at para 22, $16 \mathrm{WCB}(2 \mathrm{~d}) 239$.

${ }^{11}$ In some cases, it is clear that the scientific issues have not been properly understood. Take as an example the 7,000 lawsuits pending against Merck in respect of its drug Vioxx. In the first of the Merck Viox lawsuits to go to trail, Merck was found liable by a jury to pay U.S. $\$ 253$ million to a single claimant. Merck said the deceased did not at all fit the Vioxx risk profile because he had taken Vioxx for only a few weeks before his fatal heart attack, whereas Merck's scientific evidence suggested a danger threshold of about 18 months. Merck brought experts to court in an effort to show that there was no reputable scientific basis to the plaintiff's claim. See Ann Woolner, "A thin case against Vioxx" Ottawa Citizen (27 August 2005) B7; Similarly in $R v$ Bhatti, 2011 ONCJ 655 at para 222, 98 WCB (2d) 133 a dispute arose about the meaning of the term "speculate": "He added that 'in science, he has been taught that speculation has a higher degree of certainty to it than opinion evidence does, because opinion evidence is based on one's own opinion, where speculation takes that opinion plus the facts at hand, and establishes a new idea, a speculative idea.' He stated that it is science speak versus legal speak." 
A more insidious danger arises where the words used mean something different to those receiving them. Such subtle differences can lead to more serious misunderstandings since the miscommunication often goes unnoticed. These more subtle misunderstandings are the subject of this paper.

Perhaps the greatest danger exists where decision-makers believe they understand what is being said, but attribute significantly different meanings to the words used than those intended. The focus is of this paper is on this particular type of communication failure: one in which there is not a failure to understand but rather a misunderstanding. The danger here is perhaps greater because while a failure to understand can lead to questions and potential clarification, a misunderstanding is far less likely to be resolved. Furthermore, if scientific evidence is simply not understood, if it's received as "wah wah wah", then it is likely that little weight will be placed upon it. This is a serious concern to be sure. But in balancing probative value against prejudicial effect, more concerning still may be evidence that is misunderstood. Our study seeks to build upon existing inquiries that have shown that terms such as "match", "identical" and "consistent with" can have different meanings to those in science and law. ${ }^{12}$

We performed a study in which we presented scientists and lawyers with five words that have subtle but important differences in meaning in science and in common parlance:

\footnotetext{
${ }^{12}$ National Commission on Forensic Science "Inconsistent Terminology" (Accessed May 2015) online: <http://www.justice.gov/sites/default/files/ncfs/pages/attachments/2015/01/15/ncfs_draft_views_document_inconsis tent_terminology_final.pdf> [NCFS]. See also: National Judicial Institute, Science Manual for Canadian Judges (National Judicial Institute, 2013) [NJI]; Owen D Jones, Anthony D Wagner, David L Faigman \& Marcus E. Raichle "Neuroscientists in court" (2013) 14 Nature Rev. Neuro 730; United States, President's Council of Advisors on Science and Technology, Forensic Science in Criminal Court: Ensuring Scientific Validity of FeatureComparison Methods (Washington DC: Executive Office of the President, 2016) at 19; Dawn McQuiston-Surrett \& Michael Saks, "Communicating Opinion Evidence in the Forensic Identification Sciences: Accuracy and Impact" (2007-2008) 57 Hastings LJ 1159-1190 [McQuiston]; Gary Edmond et al, "Thinking Forensics: Cognitive Science for forensic practitioners" (2016) Sci Justice at 5.
} 
"significant", "assumption", "cannot be excluded", "evidence" and "hypothesis". We asked participants to provide definitions of these words and subjected these definitions to text analysis as well as analysis by two raters who determined if they reflected a scientific or lay view of the word. After a brief review of the prior literature on this topic, we will detail our results, which demonstrate that scientists and lawyers rely on diverging understandings of widely used terms.

\section{Efforts to develop standardized terminology}

There have been a number of attempts to develop standardized terminology that would improve communication across the scientific and legal disciplines.

(i) The United States

In the United States, at the second national meeting of the American Academy of Forensic Sciences on February 19, 2015, vice-chairs Nelson Santos of the Department of Justice and John Butler of the National Institute of Standards and Technology co-presented a status report on the work of the "Inconsistent Terminology" subcommittee, which has to date released for public comment a draft document on terms used in court to describe forensic sciences. ${ }^{13}$

Although the draft document warns against the use of obvious jargon, ${ }^{14}$ it also expresses concern about terms such as "inconclusive," "match," "consistent with," "identical," "similar in all respects tested," and "cannot be excluded as the source of". It asserts that use of these signs can have a "profound effect on how the trier of fact in a criminal or civil case perceives and evaluates scientific evidence." ${ }^{15}$ These signs are examples of non-obvious jargon, as the report

\footnotetext{
13 Ibid.

${ }^{14}$ E.g. "perimortem." "Inconsistent Terminology," NCFS, supra note 11 at 3.

15 Ibid at 1 .
} 
explains: "Even an explicit definition and statement may not be fully appreciated when terminology deviates from common usage." ${ }^{16}$ It continues: ${ }^{17}$

\footnotetext{
An example comes from a study that looked at language adopted by the American

Board of Forensic Odontology to encourage their members to use particular terms to express their conclusions. The Board defined the terms, Reasonable Scientific

Certainty, Probable, Consistent (with) and Match to express the highest to lowest

degree of similarity in a comparison analysis. When researchers asked undergraduate students to rank these terms, without being provided the ABFO's definitions, most of the students put "Match" at the top of the list.
}

The report concludes that "When a term commonly used and understood [by laymen] is redefined to have a conflicting technical meaning, the common understanding may stand in the way of comprehension and correct application." 18 This report is a useful starting point to develop a comprehensive list of terminology used by scientists in the courtroom that may cause misunderstanding. As we will emphasize below, however, it is paramount that terms with technical signifiers that concur (and not only conflict) with common understandings of the sign also be defined.

\section{(ii) $\quad \underline{\text { Canada }}$}

Canada does not have a governing national scientific body to recommend uniform scientific terminology, although the Standards Council of Canada (SCC) offers accreditation to forensic laboratories that follow recommended methodology in testing methods. The Council

\footnotetext{
${ }^{16}$ Ibid at 6.

${ }^{17} \mathrm{Ibid}$.

${ }^{18} \mathrm{Ibid}$.
} 
does not publish standards (or offer accreditation) for giving testimony or preparing reports. ${ }^{19}$

They provide no guidance on the use of scientific terminology.

In Ontario, the Ministry of Community Safety and Correctional Services’ Centre of Forensic Sciences publishes Technical Information Sheets (TISs) for each of its forensic disciplines (Biology, Chemistry, Documents, Forensic Engineering, Firearms \& Toolmarks, and Toxicology). ${ }^{20}$ These sheets explain some scientific terminology used in reports. With the exception of the Biology subgroup, the discipline-specific sheets gloss obvious jargon only. The Biology TIS gives concise, technical definitions of the non-obvious jargon terms "assumption," "attribution," “cannot be excluded," "excluded," "insufficient," and "match.",21

(iii) Standard-setting in the legal context

Legal authorities are also interested in ensuring that consistent language and effective communication is maintained between scientists and the law. In Ontario, the impetus to recommend scientific terminology for use in the courtroom has primarily been created by public commissions. The Report of the Kaufman Commission on Proceedings Involving Guy Paul Morin ("Kaufman Report") 22 and the Inquiry into Pediatric Forensic Pathology in Ontario

\footnotetext{
${ }^{19}$ See Laboratory Accreditation "Forensic Laboratories. Standards Council of Canada" (accessed May 2015) $<$ https://www.scc.ca/en/forensic> (offering accreditation for CAN-P-1578, Guidelines for the Accreditation of Forensic Testing Laboratories, Program Specialty Area: Forensic Testing Laboratories (PSA-FT); and ISO/DIS 18385.2, Minimizing the risk of human DNA contamination in products used to collect, store and analyze biological material for forensic purposes).

${ }^{20}$ See "Technical Information Sheets" (Accessed May 2015) online:

<http://www.mcscs.jus.gov.on.ca/english/centre_forensic/InformationforInvestigatorsSubmitters/TechnicalInformati onSheets/CFS_tech_sheets.html>.

${ }^{21}$ See "Technical Information Sheets-Biology" (Accessed May 2015) online:

<http://www.mcscs.jus.gov.on.ca/english/centre_forensic/InformationforInvestigatorsSubmitters/TechnicalInformati onSheets/Biology/CFS_DNA_info_tech.html>.

${ }^{22}$ Justice Fred Kaufman, Report of the Kaufman Commission on Proceedings Involving Guy Paul Morin (Toronto: Publications Ontario, 1998) [Kaufman Report].
} 
(“Goudge Inquiry") ${ }^{23}$ are two reports from such inquiries, and each made several recommendations related to scientific terminology in the courtroom. The National Judicial Institute also has published a manual on science, which includes a section on "Legal versus Scientific Terminology.",24

\section{(a) The Kaufman Report}

In 1996, the Honourable Fred Kaufman was appointed to lead a Public Inquiry into the proceedings involving Guy Paul Morin. The Commission was directed to inquire into the conduct of the investigation, the analysis of forensic evidence, and the criminal proceedings that ultimately led to Guy Paul Morin's wrongful conviction. . Among other things, the Kaufman Report noted that forensics analysts' conclusions were unclearly stated both in their reports and while being examined and cross-examined, and that subsequent overstatement of their findings by the Crown contributed to Morin's wrongful conviction. The Report contains 119 recommendations in all, three of which are relevant to the discussion of scientific terminology in the courtroom: ${ }^{25}$

Recommendation 8: ... The Centre of Forensic Sciences should endeavour to establish a policy for the use of certain uniform language which is not potentially misleading and which enhances understanding...

Recommendation 9: ... [C]ertain language is demonstrably misleading in the context of certain forensic disciplines. The terms 'match' and 'consistent with' used in the context of forensic hair and fibre comparisons are examples of potentially misleading language. CFS employees should be instructed to avoid demonstrably misleading language.

\footnotetext{
${ }^{23}$ Ontario, Inquiry into Pediatric Forensic Pathology in Ontario (2008) (Chair: Stephen T Goudge), Retrieved from < https://www.attorneygeneral.jus.gov.on.ca/inquiries/goudge/report/index.html> [Goudge Inquiry]

${ }^{24} \mathrm{NJI}$, supra note 11.

${ }^{25}$ Kaufman Report, supra note 22 at 338-345, 378 [emphasis added].
} 
Recommendation 10: Certain language enhances understanding and more clearly reflects the limitations upon scientific findings. For example, some scientists state that an item 'may or may not' have originated from a particular person or object. This language is preferable to a statement that an item 'could have' originated from that person or object, not only because the limitations are clearer, but also because the same conclusion is expressed in more neutral terms.

Recommendation 25: The Centre of Forensic Sciences' training program should be broadened to include ... formalized, ongoing programs to educate staff on ... the use of language.

In short, these recommendations seek to limit the use of misleading terminology by scientists in the courtroom, and make recommendations as to the kinds of terms that should and should not be included in the uniform terminology.

The recommendations give a few examples ("match," "consistent with," "may or may not") of the kind of terminology that should be avoided. The body of the report, particularly in Chapter II, "Forensic Evidence and the Centre of Forensic Studies," lists more. Each of the terms listed, including "match," "no dissimilarities," "similar to," "not inconsistent with," "consistent with," and "could have," ${ }^{26}$ were used by the forensic scientists in the Morin investigation and trial but were deemed misunderstood and unhelpful to the case.

Can these terms be categorized or generalized? According to Justice Kaufman, the concern with this kind of descriptive terminology lies "in the effect it creates on the minds of the jury, counsel and judges.... [A] jury cannot be expected [to] ... be attuned to the scientific nuances." ${ }^{27}$ In other words, Kaufman suggests that these terms are spoken or written with the

\footnotetext{
${ }^{26}$ Ibid at 338-345.

${ }^{27}$ Ibid at 343 (quoting Judy Bourke "Misapplied Science: Unreliability in Scientific Test Evidence" Parts I and II, (1993) 10 Aust Bar Rev 123 at 188).
} 
intention of conveying nuance, but this nuance is lost on the listeners-and what is more, the listeners are not alerted to the fact that these terms deserve special attention.

\section{(b) The Goudge Inquiry}

After confirming of a number of errors in several criminal investigations into suspicious child deaths, the Province of Ontario ordered an inquiry into the way cases involving childhood forensic pathology were handled by the justice system. The result was the Goudge Inquiry, which made recommendations to attempt to ensure that "pediatric forensic pathology supports society's interest in protecting children from harm and bringing those who do harm children before the courts" to ensure the law deals with them appropriately and serves justice. ${ }^{28}$ A major pillar of the report's recommendations is that "although it is vital that forensic pathologists be highly skilled scientists, it is equally vital that they be able to communicate their opinions effectively to the criminal justice system."29

As for communication, the report includes recommendations about forensic pathologists' use of language. Also included in the report is a glossary of medical terms. ${ }^{30}$ The glossary mostly covers medical terms that are obvious jargon from the medical profession, though it also contains definitions of "infanticide," which may be classified as non-obvious jargon because it has different meanings in the legal and forensic pathological contexts. The problem of non-obvious jargon is suggested in part 16 of the Inquiry, titled "Effective Communication with the Criminal

\footnotetext{
${ }^{28}$ Goudge Inquiry, supra note 23, at 6 .

${ }^{29}$ Ibid at 436.

${ }^{30} \mathrm{Ibid}$ at $\mathrm{xv}$ and following.
} 
Justice System," wherein the following recommendations regarding terminology and language are made: ${ }^{31}$

Recommendation $84 \mathrm{c}$ : "It is essential that the pathologist's opinion be understood by all the users. It must therefore be communicated in language that is not only accurate but also clear, plain, and unambiguous";

Recommendation $85 \mathrm{c}$ : "More generally, pathologists should be careful to express their opinions in terms that are not susceptible to varied meanings, but that do elucidate the issues addressed by the opinions";

Recommendation 96: "Forensic pathologists, in order to communicate their opinions in plain language to their lay readers, should consider including a glossary of medical terms, and, in some cases, relevant secondary literature, in their post-mortem or consultation reports"; and Recommendation 97(c)(i): "The Office of the Chief Coroner for Ontario should ... develop a Code of Practice and Performance Standards for forensic pathologists in Ontario which describes, among other things, the principles that should guide them as they write their reports.... It should ... include ... guidance on ... language to be used or avoided, and the dangers associated with the use of particular terms.

In the body of the report there is one mention of a term that may be considered nonobvious jargon: picking up on Recommendation 9 of the Kaufman Report, Justice Goudge warns that use of the phrase "consistent with," meaning "reasonably strongly supporting," is "fraught with danger" because it may be misunderstood by a trier of fact. ${ }^{32}$ Unfortunately, the report does not list other words that might potentially mislead non-expert listeners in the same way, and offers no recommendation as to how experts might identify these kinds of terms.

${ }^{31}$ Ibid at 408, 410, 427, 429-30 [emphasis added].

${ }^{32}$ Ibid at 433-35. 


\section{(c) Science Manual for Canadian Judges}

Another important recommendation from the Goudge Inquiry was the creation of a scientific manual for judges by the National Judicial Institute. ${ }^{33}$ The manual, published in 2013, includes a section on "Legal versus Scientific Terminology." 34 The section comprises a comparative lexicon, which lays out signifiers that have dual meanings in scientific and legal contexts, and a general lexicon, which defines some obvious jargon. This manual could be an excellent tool to educate judges in the overlap between scientific and legal terminology. In our view, it is still, however, a work in progress. The comparative lexicon only defines nine terms: burden of proof, evidence, fact, hypothesis, null hypothesis, standard of proof, type I error, type II error, and weight of evidence. Studies like ours could be used to expand the comparative lexicon and to set out terms and phrases to avoid as well as suggested alternatives.

\section{A study on legal and scientific jargon}

\section{$\underline{\text { Purpose and Overview }}$}

Despite the concerns presented by the commissions and organizations above, there has been little systematic academic research on the divergent lay and scientific meanings of words frequently used in courts and tribunals. Existing research has narrowly focused on the misunderstandings that may arise from jargon usage in specific forensic disciplines, such as fingerprint,${ }^{35}$ hair, and bitemark analysis. ${ }^{36}$ In an attempt to fill this lacuna, we performed the

\footnotetext{
${ }^{33}$ Ibid at 502.

${ }^{34}$ NJI, supra note 11 at 107.

${ }^{35}$ Brandon Garrett \& Gregory Mitchell, "How Jurors Evaluate Fingerprint Evidence: The Relative Importance of Match Language, Method Information, and Error Acknowledgment”10:3 Journal of Empirical Legal Studies 484511.

${ }^{36}$ McQuiston, supra note 10; and for a review on research regarding scientific and lay understandings of probability statements, see: Kristy A Martire et al, "The psychology of interpreting expert evaluative opinions” (2013) 45:3
} 
present study. It examines misunderstandings that may arise between scientists and legallytrained individuals in relation to commonly-used words with diverging scientific and lay meanings.

We presented a sample of lawyers and scientists with five words: "significant", "assumption", "cannot be excluded", "evidence" and "hypothesis".). The "lawyer" group all had formal legal education and no higher-level scientific education. Hence they were "laymen" or "non-experts" in relation to scientific knowledge. The "scientist" group all had formal higher education in an experimental science (in contrast to social science) discipline. ${ }^{37}$

We hypothesized that each word and phrase would have a technical connotation within the scientific community and a different meaning in lay/legal usage. We predicted differing definitions along the following lines:

\section{Assumption}

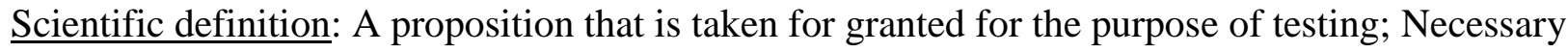
to scientific testing

Lay/Legal definition: A mere guess; an unsubstantiated claim; mere speculation

\section{Cannot be excluded}

Scientific definition: Is included. It's a match.

Lay/Legal definition: Can't be ruled out for sure, but probably is not included.

\section{Significant result}

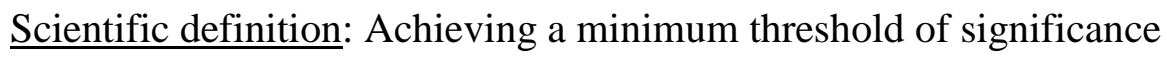

305-314. See also: Dias, M., Boehmer, S., Johnston-Walsh, L., \& Levi, B. (2015). Defining "reasonable medical certainty" in court: What does it mean to medical experts in child abuse cases? Child Abuse \& Neglect, 50, 218227. doi:10.1016/j.chiabu.2015.10.027 and De Keijser, J., Malsch, M., Luining, E., Kranenbarg, M., \& Lenssen, D. (2016). "Differential reporting of mixed DNA profiles and its impact on jurists' evaluation of evidence. An international analysis". Forensic Science International: Genetics, 23, 71-82. doi:10.1016/j.fsigen.2016.03.006.

${ }^{37}$ We categorized physics, chemistry, biology and related fields as "experimental science" disciplines. 
Lay/Legal definition: A categorically important result

\section{Evidence}

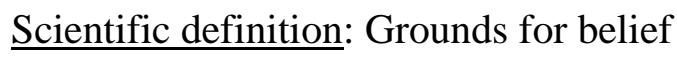

Lay/Legal definition: Information presented by either side to the court which may or may not be believable

\section{Hypothesis}

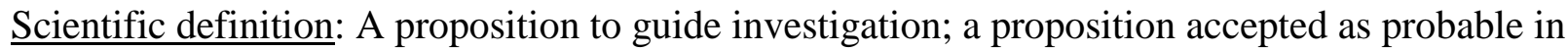
light of established facts

Lay/Legal definition: A mere guess; a supposition; an unsubstantiated claim

As to our own hypotheses, we suspected that scientists and lawyers would approach the above words in a predictably different manner. Taking an open-scientific ${ }^{38}$ and evidence-based ${ }^{39}$ approach to the question, we generated scientific and lay/legal definitions for the words above according to our own observations in the field (i.e., a "coding guide"; see Appendix 1).We then asked a group of scientists and lawyers to provide their own definitions for those words. For “assumption”, we also asked, as a true or false question, if assumptions should generally be avoided because we hypothesized that lawyers would frown upon assumptions to a greater degree.

We then asked two raters, blind to whether the definition came from a lawyer or scientist, to rate those definitions as scientific or lay/legal based on our coding guide. The raters also

\footnotetext{
${ }^{38}$ Several recent findings have put the reproducibility of portions of the psychological scientific literature into doubt. For instance, see: D Stephen Lindsay, "Replication in Psychological Science" (2015) 26:12 Psychological Science 1827-1832. Researchers agree that one source of the reproducibility problem is lack of transparency in how studies are performed and how the data is presented. As a result, they prescribe more transparent and widely accessible practices (i.e., open). See: Brian A Nosek et al, "Promoting an open research culture" (2015) 348:6242 Science 1422-1425. In the current study we adopted an open and reproducible approach. We preregistered our hypotheses and have made our data and analyses open to scrutiny (but de-identified). Find both online at $\langle$ https://osf.io/j74rp/ $>$. ${ }^{39} \mathrm{By}$ evidence-based, we mean that rather than presume there is a misunderstanding about a term, we empirically tested whether that is the case.
} 
evaluated the responses for their attitude towards the words because, as noted above, we suspected lawyers would have a more negative attitude toward assumptions and hypotheses (see Appendix 1). Further, we subjected the participant-generated definitions to text analysis to determine if they used different words in generating their definitions.

(ii) $\quad \underline{\text { Procedure }}$

\section{(d) Materials}

We developed a survey asking participants to provide definitions of the five words above, and respond to the true-false question about assumptions. They were asked to provide up to three definitions of the target words, beginning with the first that came to mind. They also answered several questions about their educational background, including legal and scientific courses taken in high school and university, and the number of years they have practiced law (if applicable). ${ }^{40}$ The survey was administered online via Survey Monkey.

We also developed a coding guide to classify the definitions on a 5-pointscale (see Appendix 1). The definitions were classified as completely scientific (1) to completely (5) legal Definitions that were an equal mix of legal and scientific elements were coded as a 3. Definitions that were mostly scientific were coded with a 2 and those that were mostly lay were given a 4 . Attitude was coded similarly, with completely positive coded as 5 and completely negative coded as 1 .

\footnotetext{
${ }^{40}$ The full survey is available online < https://www.surveymonkey.com/r/?sm=62HFwBagpWyRHjL5lm83Dc6EP30FCcMVjVIOLVgU_2Bf0_3D>.
} 


\section{(e) Participants}

We performed a power analysis to determine the number of participants we would require. ${ }^{41}$ To determine what effect size we should expect, we reviewed the literature on the effect of education on vocabulary. These studies show a medium to large effect. ${ }^{42}$ Thus, assuming a Cohen's $\mathrm{d}$ of .6 and seeking power of .8 and a type I error rate of .05 , we determined we needed at least 45 participants per condition.

Participants in the law sample were recruited by e-mail from the Canadian office of a large international corporate law firm. Participants in the science sample were recruited from a Canadian university's student and alumni association.

Ultimately, 122 participants completed the survey: 66 from the science sample and 56 from the law sample. Note that because we only studied lawyers and scientists, we cannot make any conclusion about differences between lawyers and non-lawyers. And as we suggest below, lawyers may think about some of these terms differently than the public.

(iii) $\quad \underline{\text { Results }}$

To determine the effect of scientific or legal background on terminology use, we performed two types of analysis. First, we performed a text analysis, examining the frequency of the words used by our scientific and legal samples in constructing their definitions. Second, we

\footnotetext{
${ }^{41}$ Power is the probability of discovering an effect when one exists, see: Geoff Cumming, "The New Statistics: Why and How" (2014) 25:7 Psychological Science 8-29 at 10.

42 e.g., see: Joseph D Matarazzo \& David O Herman, "Relationship of Education and IQ in the WAIS-R Standardization Sample” (1984) 52: 4 Journal of Consulting and Clinical Psychology 631-634); Paul Verhaeghen, "Aging and Vocabulary Scores: A Meta-Analysis" (2003) 18:2 332-339.
} 
performed analyses using the ratings provided by the two blind coders. We report the results of these two sets of analysis below.

\section{(a) Manipulation check}

A manipulation check is a test to verify that experimental manipulation has had some preliminary effect. We performed a manipulation check to determine if our science and law samples indeed reflected the characteristics they were sampled for (i.e., greater scientific education in the science sample and legal education in the law sample). ${ }^{43}$ These analyses demonstrated that indeed, the science sample had taken more science courses in both high school, $\mathrm{t}(119)=2.38, p=.020$, and in post graduate studies, $\mathrm{t}(1119)=5.87, p<.001$. Similarly, the lawyers had both more legal education, $\mathrm{t}(116)=3.41, p<.001)$, and more years in practice, $\mathrm{t}(116)=7.67, p<.001$. No member of the science sample had engaged in any legal practice.

\section{(b) Text Analysis}

We employed text analysis to explore patterns of word usage in the science and law samples. As we will describe below, the science and law groups approached the words we provided with different lexicons. This analysis was ultimately confirmed by a Naïve Bayes machine learning algorithm, which was able to reliably classify the definitions provided by participants as coming from a lawyer or scientist based on the diction they used.

Table 1 displays the ten most frequently used terms that participants used in generating their definitions. ${ }^{44}$ This table is divided by both the word being defined and the participant's

\footnotetext{
${ }^{43}$ Available online <https://osf.io/tj36s/>.

${ }^{44}$ Full analysis available online $<$ https://osf.io/nsz2s/>.
} 
status as lawyer or scientist. For example, the first two columns compare word use by lawyers and scientists across all definitions (i.e., the omnibus analysis), and the second set of columns compares word use for the definition of "significant". ${ }^{45}$ Word usage between groups was visibly different on several words. We tested these differences in the following analyses.

\section{Omnibus}

In the omnibus (i.e., an analysis comparing the two groups based on their usage of all the words, rather than specific words) analysis, we discerned three statistically significant differences. ${ }^{46}$ The lawyers were more likely than the scientists to use the word "fact" or "facts", $\chi^{2}=16.60, p<.001$, and "theory", $\chi^{2}=9.47, p=.006$. The scientists were more likely to use the word "data", $\chi^{2}=9.78, p=.004$. Lawyers were marginally more likely to use "conclusion", $\chi^{2}=$ $5.09, p=.096$.

\section{Significant}

Focusing on just definitions for "significant", ${ }^{47}$ we found that lawyers were more likely to use the word "meaningful", $\chi^{2}=8.92, p=.003$. We also note that 3 lawyers and no scientists used the term "material" in their definitions.

\footnotetext{
${ }^{45}$ The omnibus comparison was generated to be broad and thus includes all words used across all three definitions provided by participants. The specific word comparisons are more focused and thus only include the words from the first definition provided by participants. The word "statistic", "statistical" and "statistically" are collapsed into one word for all comparisons.

${ }^{46} \mathrm{We}$ applied a Holm correction to all reported p-values to control for multiple comparisons, with the lowest p-value multiplied by one, the second lowest multiplied by two, and so on. See: Sture Holm, "A Simple Sequentially Rejective Multiple Test Procedure" (1979) 6 Scandinavian Journal of Statistics 65-70.

${ }^{47}$ Ibid.
} 


\section{Assumption}

Regarding "assumption", ${ }^{48}$ lawyers were more likely to use the word "fact", $\chi^{2}=4.95, p$ $=.026$.

\section{Cannot be excluded}

For "cannot be excluded", ${ }^{49}$ lawyers were more likely to use the word "must", $\chi^{2}=11.43$, $p<.001$, and "included" $\chi^{2}=6.66, p<.001$. A visual review of the raw data confirms that these participants were indicating that if something could not be excluded, it "must be included" in a decision process.

\section{Evidence}

For the term "evidence", ${ }^{50}$ the lawyers were more likely to use "fact" or "facts", $\chi^{2}=$ $5.36, p=.021$ and marginally more likely to use proof "proof", $\chi^{2}=3.92, p=.096$.

\section{Hypothesis}

For the term "hypothesis", ${ }^{51}$ the lawyers were more likely to use "tested", $\chi^{2}=5.57, p=$ .018 .

We sought to test these apparent differences in a more rigorous manner. To do so, we employed a Naïve Bayesian classifier. ${ }^{52}$ These classifiers assign observations to a most likely

\footnotetext{
48 Ibid.

${ }^{49}$ Ibid.

${ }^{50}$ Ibid.

${ }^{51}$ Ibid.

52 David J Hand and Keming Yu, “Idiot's Bayes-Not So Stupid After All?” (2001) 69:3 International Statistical Review 385-398 [Hand]; We adapted the algorithm provided online by Jesus M Castagentto at
} 
class based on their features (e.g., the words used and their relative frequency). In the first stage of the analysis, the algorithm is trained on a portion of the data set. It attempts to learn the words that are associated with a certain class (here, scientists or lawyers). Then, on the remainder, the algorithm predicts the classification based on the data. We surmised that if a Naïve Bayesian classifier could be trained to accurately predict whether a respondent was a lawyer or scientist based only on the words they used, this would be persuasive evidence for the proposition that these two groups write and think about these words differently. Despite their simplicity, several reviews of the accuracy of Naïve Bayesian classifiers find they are extremely successful: "numerous variations of naive Bayes models have been used, producing some of the best results."

We trained a Naïve Bayesian classifier using $75 \%$ of our omnibus data to see if it could predict the other $25 \%$ accurately. We found the classifier was accurate, correctly predicting group membership based on the word usage $82.5 \%$ of the time, $95 \%$ CI $[67.22 \%, 92.66 \%], p<$ .001. This finding demonstrates that the scientists and lawyers in our sample used a different lexicon when seeking to define our target words. The Naïve Bayes's results converge with two findings from our analysis of the coded responses.

$<$ https://rpubs.com/jesuscastagnetto/caret-naive-bayes-spam-ham-sms >; see our full script online at $<$ https://osf.io/pfnq8/>.

${ }^{53}$ David D Lewis, "Naive (Bayes) at forty: The independence assumption in information retrieval." (1998) European conference on machine learning 4-15 at 12; and see Hand, ibid at 395: "[Naïve Bayes] seems often to perform surprisingly well. There are sound reasons for this: its intrinsic simplicity means low variance in its probability estimates; although these will typically be biased, this may not matter in classification situations as long as the rank order is preserved; in many situations the variables have undergone a selection process which tends to reduce their interdependencies; moreover simple extensions of the basic independence structure can be adopted which improve its performance" 


\section{(c) Coded-Response Analysis}

Prior to measuring the differences in coded ratings, we first determined the interrater reliability of the two coders' ratings using Cohen's Kappa. ${ }^{54}$ Focusing on just the first definition provided, ${ }^{55}$ we found moderate ${ }^{56}$ agreement for the word "assumption" $(\kappa=.523)$ and substantial agreement for the words "significant" $(\kappa=.71)$ and "cannot be excluded" $(\kappa=.666)$. There was only slight agreement over "evidence" $(\kappa=.149)$ and fair agreement over "hypothesis" $(\kappa=.29)$.

Interrater reliability of attitude ratings towards the target words was poor to fair and thus we did not pursue further analyses of these ratings. Similarly, we did not further analyze definitional ratings of "evidence" and "hypothesis" for lack of interrater agreement on those terms. For the remainder of the terms (i.e., assumption, significant, and cannot be excluded), we averaged the two coders ratings.

We uncovered two statistically significant differences for the ratings of the definitions. ${ }^{57}$ For the definition of "significant", scientists $(\mathrm{m}=2.69, \mathrm{SD}=1.22)$ provided a definition that better matched the scientific definition than did lawyers $(\mathrm{m}=3.20, \mathrm{SD}=1.31), \mathrm{t}(112)=2.20, p=$ $.03,95 \%$ CI $[.05, .97]$.

Second, and contrary to our expectations, lawyers $(\mathrm{m}=2.25, \mathrm{SD}=1.29)$ provided a definition of "cannot be excluded" that better matched the scientific definition than did scientists

\footnotetext{
54 Jacob Cohen, “A coefficient of agreement for nominal scales" (1960) 20 Educational and Psychological Measurement 37-46; Mary L McHugh, "Interrater reliability: the kappa statistic." (2012) 22:3 Biochemia medica 276-282.

55 Very few participants provided more than one definition, resulting in a small sample size for secondary and tertiary definitions.

${ }^{56}$ We relied on the widely-used but subjective standard found in J Richard Landis \& Gary G Koch, "The Measurement of Observer Agreement for Categorical Data" 33 Biometrics 159-174 at 165 wherein a $\kappa<0$ is poor and "0.00-0.20 Slight; 0.21-0.40 Fair; 0.41-0.60 Moderate; 0.61-0.80 Substantial; 0.81-1.00 Almost Perfect"; all analyses are available online at $\langle$ https://osf.io/s692q/>.

${ }^{57}$ All analyses are available online at <https://osf.io/xw5m9/>.
} 
$(\mathrm{m}=3.14, \mathrm{SD}=1.20), \mathrm{t}(110)=-3.86, p<.001,95 \%$ CI $[-.43,-1.34]$. Lawyers and scientists did not provide statistically significantly different definitions of "assumption", $p=.84$.

(d) Acceptability of Assumptions?

We did not observe any difference between lawyers and scientists in response to the question of whether it is better to not make assumptions. Responses were nearly identical with $87.80 \%$ of lawyers agreeing it was better to not make assumptions compared to $89.02 \%$ of scientists.

(iv) Discussion

Our findings present both important insights and guidance for future research. Most notably, we were able to use a machine learning program to reliably determine whether the author of a set of definitions was a lawyer or scientist based only on the terminology they used. This finding demonstrates that scientists and lawyers approach at least some of the terms we used with diverging lexicons, presenting the opportunity for unperceived misunderstanding. Generally, lawyers were more likely to conceive of these words as establishing "fact", whereas scientists were more loathe to use that term. ${ }^{58}$ Scientists, on the other hand, are more likely to couch their definitions in terms of "data". A similar pattern appeared across analysis of the individual words.

We found disagreement in our text analysis and ratings of trained coders in the terms "significant" and "cannot be excluded". For "significant", the lawyers were more likely to use

\footnotetext{
${ }^{58}$ Indeed, establishing "facts" in the adjudication of a dispute is one of the most important parts of a lawyer's job. It thus follows that they would be more likely to use this word. See, generally: William Twining, "Taking Facts Seriously-Again" (2005) 55 Journal of Legal Education 360-380.
} 
the term "meaningful" and adopt a categorical approach. Scientists, however, felt that it merely indicated that a threshold was met. Similarly, lawyers ascribed a more definitive meaning to "cannot be excluded", but contrary to our expectation suggested that it meant that something must be included. Scientists used more equivocal language. This divergence between our expectation and the actual results can likely be explained by context-dependency. That is, we correctly predicted that scientists would use more equivocal language to define the phrase but incorrectly predicted the direction in which lawyers would ascribe their definitiveness. They were thinking of a situation significantly suggesting inclusion rather than exclusion. Most important, however, is the clear divergence between the two groups in terms of assigning equivocal as opposed to definitive interpretations.

Methodologically, we hope we have demonstrated a useful approach that the governmental and quasi-governmental bodies mentioned above may pursue. Text analysis and machine learning represent a powerful and underused way to study divergences in the way in which scientists and the legal community think and write about science. As such, we have made all of our (de-identified) data and analysis scripts public and available for broader use, perhaps to use this approach to study a wider range of terms. In particular, a vast body of text already exists: judicial decisions. Future research may subject those decisions to our method. A future study might, for instance, explore whether scientific language in decisions predicts the outcome of that decision (e.g., are scientifically sophisticated decisions more likely to hold scientific evidence to a more rigorous standard?). ${ }^{59}$

\footnotetext{
${ }^{59}$ For example, Margaret Bull Kovera \& Bradley D McAuliff "The effects of peer review and evidence quality on judge evaluations of psychological science: Are judges effective gatekeepers?” (2000) 85:4 Journal of Applied
} 
Similarly, the difficulty we encountered in coding cases for their attitude towards the word and for their scientific-slant may provide a cautionary tale. More specifically, our coders were unable to agree on whether the definitions provided by participants demonstrated a negative or positive attitude towards the word. Future studies may instead provide the target word in context (e.g., "the scientist's findings relied on several assumptions about human nature") rather than in the abstract, to explore subtle attitudinal differences towards those words. Similarly, our text analysis (see Table 1) may assist in developing a more robust coding scheme: visibly different patterns emerged from the ways in which our participants described the target words. We did not, however, make a priori predictions about these precise patterns. Future studies can both replicate our findings and expand upon them to explore additional terms and contexts likely to lead to misunderstandings between the legal and scientific communities. Once identified, these likely sources of confusion can be quite easily avoided in favour of clearer alternatives.

\section{Conclusion}

As science continues to learn more about the world, few areas will remain beyond its reach. It will become increasingly difficult to find legal trials where scientific evidence will not have something relevant to add. As a result, it will become all the more important for the legal system to do everything it can to maximize the understanding of scientific evidence and minimize misunderstandings. Avoiding ambiguous terminology is a relatively easy way to reduce misunderstandings. We think this can best be accomplished by studies such as this one that use a rigorous methodology to identify terms likely to raise mutual misunderstanding. Once identified, these terms can then be avoided. Alternative words and phrases can then be 
suggested.Small but significant changes can be made by educating judges and lawyers and amending jury charges, as well as subtly changing the way in which experts present their evidence. Ultimately, it is law schools that could effect the greatest change by including in the legal curriculum some basic education about how to understand statistical information and avoid common misconceptions. 


\section{Appendix 1}

Appendix 1. The coding sheet used by two coders.

Instructions: For all the terms below, choose a number from 1-5 to represent whether the definition provided was closer to the scientific definition, or to the legal definition.

\begin{tabular}{|l|l|l|l|l|}
\hline \multicolumn{1}{|c|}{1} & \multicolumn{1}{|c|}{2} & \multicolumn{1}{c|}{3} & \multicolumn{1}{c|}{5} \\
\hline $\begin{array}{l}\text { It is completely, } \\
\text { or almost } \\
\text { completely the } \\
\text { scientific } \\
\text { definition }\end{array}$ & $\begin{array}{l}\text { It is mostly the } \\
\text { scientific } \\
\text { definition with } \\
\text { some elements of } \\
\text { the legal } \\
\text { definition }\end{array}$ & $\begin{array}{l}\text { It is an equal mix } \\
\text { of the scientific } \\
\text { and legal } \\
\text { definitions }\end{array}$ & $\begin{array}{l}\text { It is mostly the } \\
\text { legal definition } \\
\text { with some } \\
\text { elements of the } \\
\text { scientific } \\
\text { definition }\end{array}$ & $\begin{array}{l}\text { It is completely } \\
\text { or almost } \\
\text { completely the } \\
\text { legal definition }\end{array}$ \\
\hline
\end{tabular}

For all the terms below, choose a number from 1-5 to represent your assessment of the participant's attitude towards the term, based on the definition they provided.

\begin{tabular}{|l|l|l|l|l|}
\hline \multicolumn{1}{|c|}{1} & \multicolumn{1}{|c|}{2} & \multicolumn{1}{c|}{3} & \multicolumn{1}{c|}{5} \\
\hline $\begin{array}{l}\text { A strongly } \\
\text { negative attitude }\end{array}$ & $\begin{array}{l}\text { A moderately } \\
\text { negative attitude }\end{array}$ & $\begin{array}{l}\text { Neither negative } \\
\text { nor positive }\end{array}$ & $\begin{array}{l}\text { A moderately } \\
\text { positive attitude }\end{array}$ & $\begin{array}{l}\text { A strongly } \\
\text { positive attitude }\end{array}$ \\
\hline
\end{tabular}

\section{Assumption}

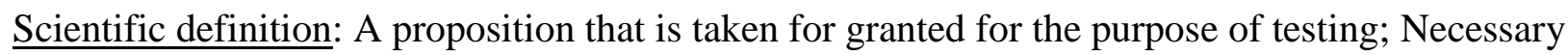
to scientific testing

Lay/Legal definition: A mere guess; an unsubstantiated claim; mere speculation

\section{Cannot be excluded}

Scientific definition: Is included. It's a match.

Lay/Legal definition: Can't be ruled out for sure, but probably is not included.

\section{Significant result}

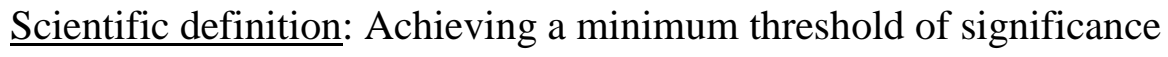

Lay/Legal definition: A categorically important result

\section{Evidence}

$\underline{\text { Scientific definition: Grounds for belief }}$ 
Lay/Legal definition: Information presented by either side to the court which may or may not be believable

\section{Hypothesis}

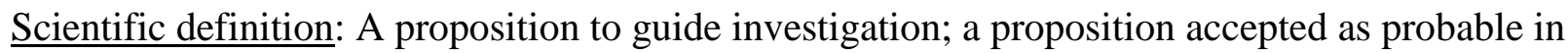
light of established facts

Lay/Legal definition: A mere guess; a supposition; an unsubstantiated claim 


\section{Table 1}

Table 1. Word usage ordered by frequency. The results are divided first by word and then by sample: law or science. Frequency is in parentheses.

\begin{tabular}{|c|c|c|c|c|c|c|c|c|}
\hline \multirow[t]{2}{*}{ Order } & \multicolumn{2}{|l|}{ Omnibus } & \multicolumn{2}{|l|}{ "Significant" } & \multicolumn{2}{|l|}{ "Assumption" } & \multicolumn{2}{|c|}{ "Cannot be excluded" } \\
\hline & $\underline{\text { Law }}$ & $\underline{\text { Science }}$ & $\underline{\text { Law }}$ & $\underline{\text { Science }}$ & $\underline{\text { Law }}$ & Science & Law & Science \\
\hline 1 & $\begin{array}{l}\text { Theory } \\
(35)^{* *}\end{array}$ & Result (59) & $\overline{\text { Result (19) }}$ & $\begin{array}{l}\text { Result } \\
(36)\end{array}$ & Without (16) & True (19) & $\begin{array}{l}\text { Must } \\
(\mathbf{2 5})^{* * * *}\end{array}$ & $\begin{array}{l}\text { Included } \\
(14) * * *\end{array}$ \\
\hline 2 & Result (31) & $\begin{array}{l}\text { Evidence } \\
\text { (45) }\end{array}$ & Outcome (12) & $\begin{array}{l}\text { Statistic } \\
(24)\end{array}$ & Fact $(15)^{*}$ & $\begin{array}{l}\text { Without } \\
\text { (18) }\end{array}$ & $\begin{array}{l}\text { Included } \\
(21)^{* * * *}\end{array}$ & $\begin{array}{l}\text { Something } \\
\text { (14) }\end{array}$ \\
\hline 3 & $\begin{array}{l}\text { Something } \\
(30)\end{array}$ & $\begin{array}{l}\text { Something } \\
\text { (44) }\end{array}$ & Statistic (12) & $\begin{array}{l}\text { Chance } \\
\text { (12) }\end{array}$ & True (14) & $\begin{array}{l}\text { Evidence } \\
\text { (17) }\end{array}$ & $\begin{array}{l}\text { Something } \\
(6)\end{array}$ & $\begin{array}{l}\text { Must } \\
(13)^{* * * *}\end{array}$ \\
\hline 4 & Must (28) & True (34) & Important (8) & $\begin{array}{l}\text { Importan } \\
\mathrm{t}(11)\end{array}$ & $\begin{array}{l}\text { Something } \\
\text { (13) }\end{array}$ & $\begin{array}{l}\text { Somethin } \\
\mathrm{g}(16)\end{array}$ & Left (5) & $\begin{array}{l}\text { Considered } \\
\text { (8) }\end{array}$ \\
\hline 5 & $\begin{array}{l}\text { Fact } \\
(\mathbf{2 6})^{* * *}\end{array}$ & $\begin{array}{l}\text { Data } \\
(31)^{* * *}\end{array}$ & $\begin{array}{l}\text { Meaningful } \\
(8)^{* *}\end{array}$ & $\begin{array}{l}\text { Significa } \\
\text { nt (8) }\end{array}$ & Based (9) & $\begin{array}{l}\text { Based } \\
(10)\end{array}$ & $\begin{array}{l}\text { Possible } \\
(6)\end{array}$ & $\begin{array}{l}\text { Possibility } \\
\text { (8) }\end{array}$ \\
\hline 6 & $\begin{array}{l}\text { Conclusion } \\
\text { (23) }\end{array}$ & $\begin{array}{l}\text { Statistic } \\
(28)\end{array}$ & Finding (6) & $\begin{array}{l}\text { Unlikely } \\
\text { (6) }\end{array}$ & Evidence (9) & $\begin{array}{l}\text { Conclusi } \\
\text { on }(10)\end{array}$ & Group (4) & $\begin{array}{l}\text { Evidence } \\
\text { (7) }\end{array}$ \\
\hline 7 & $\begin{array}{l}\text { Included } \\
(23)\end{array}$ & Based (25) & Significant (5) & Due (5) & $\begin{array}{l}\text { Conclusion } \\
\text { (7) }\end{array}$ & $\begin{array}{l}\text { Situation } \\
\text { (7) }\end{array}$ & $\begin{array}{l}\text { Considered } \\
\text { (3) }\end{array}$ & $\begin{array}{l}\text { Possible } \\
\text { (6) }\end{array}$ \\
\hline 8 & True (23) & Guess (25) & Certain (3) & $\begin{array}{l}\text { Hypothes } \\
\text { is }(5)\end{array}$ & $\begin{array}{l}\text { Information } \\
\text { (7) }\end{array}$ & $\begin{array}{l}\text { Statemen } \\
\mathrm{t}(6)\end{array}$ & May (3) & Ruled (5) \\
\hline 9 & $\begin{array}{l}\text { Facts } \\
(\mathbf{2 2})^{* * *}\end{array}$ & $\begin{array}{l}\text { Theory } \\
(24) * *\end{array}$ & Material (3) & $\begin{array}{l}\text { Significa } \\
\text { nce }(5)\end{array}$ & Taken (7) & Truth (6) & Might (3) & Rule (4) \\
\hline 10 & $\begin{array}{l}\text { Information } \\
\text { (21) }\end{array}$ & $\begin{array}{l}\text { Hypothesis } \\
(23)\end{array}$ & $\begin{array}{l}\text { Consequence } \\
\text { (2) }\end{array}$ & True (5) & Make (4) & Fact (5) & $\begin{array}{l}\text { Necessary } \\
\text { (3) }\end{array}$ & True (4) \\
\hline
\end{tabular}

\begin{tabular}{|c|c|c|c|c|}
\hline & $\frac{\text { "Evidence" }}{\text { Law }}$ & & "Hypothesis" & \\
\hline 1 & $\frac{\text { Law }}{\text { Facts }}(15) *$ & $\frac{\text { Science }}{\text { Data (15) }}$ & $\frac{\text { Law }}{\text { Theory (23) }}$ & $\begin{array}{l}\text { Science } \\
\text { Theory } \\
\text { (17) }\end{array}$ \\
\hline 2 & Proof (15) & $\begin{array}{l}\text { Informatio } \\
\mathrm{n}(15)\end{array}$ & Guess (14) & $\begin{array}{l}\text { Evidence } \\
\text { (12) }\end{array}$ \\
\hline 3 & $\begin{array}{l}\text { Support } \\
(10)\end{array}$ & Facts (13) & Tested (13)* & $\begin{array}{l}\text { Guess } \\
(10)\end{array}$ \\
\hline 4 & $\begin{array}{l}\text { Information } \\
\text { (9) }\end{array}$ & $\begin{array}{l}\text { Hypothesis } \\
\text { (13) }\end{array}$ & Educated (8) & $\begin{array}{l}\text { Explanati } \\
\text { on (8) }\end{array}$ \\
\hline 5 & $\begin{array}{l}\text { Conclusion } \\
\text { (8) }\end{array}$ & $\begin{array}{l}\text { Support } \\
(13)\end{array}$ & Based (7) & Idea (8) \\
\hline 6 & $\operatorname{Fact}(8) *$ & Proof (9) & Idea (7) & $\begin{array}{l}\text { Proposed } \\
\text { (6) }\end{array}$ \\
\hline 7 & $\begin{array}{l}\text { Something } \\
\text { (7) }\end{array}$ & $\begin{array}{l}\text { Something } \\
\text { (8) }\end{array}$ & Evidence (5) & $\begin{array}{l}\text { Statemen } \\
\mathrm{t}(6)\end{array}$ \\
\hline 8 & $\begin{array}{l}\text { Hypothesis } \\
\text { (6) }\end{array}$ & Theory (7) & $\begin{array}{l}\text { Information } \\
\text { (5) }\end{array}$ & $\begin{array}{l}\text { Tested } \\
(6)\end{array}$ \\
\hline 9 & $\begin{array}{l}\text { Supporting } \\
\text { (6) }\end{array}$ & $\begin{array}{l}\text { Supports } \\
\text { (6) }\end{array}$ & One (4) & $\begin{array}{l}\text { Working } \\
\text { (6) }\end{array}$ \\
\hline 10 & $\begin{array}{l}\text { Argument } \\
\text { (4) }\end{array}$ & $\begin{array}{l}\text { Argument } \\
\text { (7) }\end{array}$ & $\begin{array}{l}\text { Conclusion } \\
\text { (3) }\end{array}$ & Made (5) \\
\hline
\end{tabular}

